\title{
1. Introduction to Hiding in Plain Sight: Uncovering Nuclear Histories
}

\section{Robert Anderson}

This is a trans-disciplinary conversation among scholars involved in a variety of nuclear studies and is particularly focused on their encounters with both vast archives and scarce archives.

We are aware of scholars in Canada and elsewhere who are interested in areas as diverse as the history of nuclear diplomacy; technical aspects of nuclear weapons; treaties for nuclear disarmament and arms control; international and/or comparative studies of nuclear energy; storage of nuclear waste; studies of extractive and/or Indigenous "nuclear communities"; sociology of nuclear and expert relations; comparisons of nuclear and alternate forms of energy; and how the media have dealt with nuclear risk. Despite the importance of these specific topics in the contemporary world, we feel that the broader idea of nuclear studies and the possible synergies between these different areas of work is curiously neglected in Canada. This is our chief motivation: to present a group of essays devoted to the discussion of this broad subject mostly in relation to its secretive origins and the absence of records.

\section{Themes and Issues}

Official secrets and sensitive evidence have been kept in closed files for generations and have also been opened gradually. In Canada, the waiting period has usually been thirty years after their use. But nuclear affairs were seldom included in that general rule of opening the records. Since the mid-1980s, however, some sensitive Canadian documents have been opened 
on request for study, following passage of the Access to Information Act in 1983. Researchers gained access to sets of closed documents from the 1940s onward. Soon many of these nuclear files were, after review, declared open. Other files from the same period, however, remained closed. Thus, Canada's long history of nuclear development, international negotiation and involvement in bilateral global agreements has resulted in a vast and valuable archive that is, though greatly more open each year, still largely untapped and undervalued.

In the recent depiction of Canada's history for the country's 150th anniversary in 2017, there was no reference in the media to Canada's important nuclear history. In textbooks for grade twelve students, there is almost no mention of Canada's role in nuclear developments, whether in the uranium trade or reactor design, or in the special public-private collaboration embedded in the entire Canadian nuclear system. Even Canada's efforts in nuclear arms control and disarmament went largely unrecognized during that anniversary. Although Canada passed an anniversary of one hundred fifty years as a national state, recognition of our complex nuclear past was limited to passing references to nuclear facilities like Chalk River and organizations like Atomic Energy of Canada Limited, Canadian Nuclear Laboratories, and the Canadian Nuclear Safety Commission. While recognition of these entities is appropriate, their very limited reference reminds a relatively uninformed public that this particular history is not important in "a free and democratic society." On the contrary, l'd say that if Canadians are confused by or conflicted over this history then they need to understand it better. It is one of our deeper links with the rest of world in the twentieth century. And for that understanding we need to open the archives sooner and steadily, and let people know about them. 
Nuclear scholars tend to gather from time to time as a form of renewal of energies. The SSHRC-funded April 2012 Workshop at the University of Toronto was coordinated by Laurel MacDowell as described in her Chapter 2 here. The workshop addressed "The Nuclear Industry in the 21st Century: How We Got Here," showed that emerging young researchers were keenly interested in understanding not just the familiar geopolitical nuclear chess game at the heart of the nuclear world since the 1940s Cold War, but also the social history, business history, environmental history, labour history, Indigenous history of different nuclear communities and the whole nuclear industry from the 1940s onward. Following that Toronto Workshop in 2012, a new network called the Nuclear International Research Group (NIRG) was founded. Then, in 2018 and 2019, workshops ${ }^{1}$ which the authors of this publication attended were an extension and enlargement of that question: How did we get here?

Not all of these essays are about Canada alone; some connect Canada and India, some are about Japan, Ukraine, and/or India, a number are about United States - even referring to the deep connections between Canadian and American nuclear affairs. They reflect the fact that the records of nuclear studies are a uniquely twentieth century archive. In these essays, we are recognizing that special history, having gathered together some of the evidence that will give the next generation a better sense of what happened, how it happened and why it happened. From many public points of view, Canada's nuclear histories should all become slightly less mysterious. Our title, Hiding in Plain Sight, is lifted posthumously from archivist and historian Greg Donaghy's abstract for the paper he could not write, as explained in Chapter 3. I toyed with a title Hidden in Plain Sight but realized that "hidden" implied human agency in 
every case, as if hidden by someone. It also suggests an activity in the past. But that is not true

for all our cases in this collective work; some of this hiding is occurring today and will be done tomorrow; some of it a result of agency, some not.

Now that the NIRG had become the "Nuclear Humanities and Social Sciences" and is profiled on the website of the CNRS of France where it is known as "Nuclear_hss," it has an truly global reach. To extend and deepen that reach, we dedicate these short essays with pleasure.

Robert Anderson, Editor, Professor Emeritus, School of Communication, Simon Fraser University

${ }^{1}$ I am most grateful to Social Science \& Humanities Research Council of Canada for their support to Simon Fraser University which enabled us to stage these workshops at the National Library and Archive of Canada in Ottawa in June 2018 and at the 2019 Congress of Humanities and Social Sciences at the University of British Columbia. Equally important, the School of Communication managed the accounting of these workshops with me. I am also indebted to MV Ramana, Director of the Liu Institute of Global Issues and to the President of Green College - both at UBC - for enabling us to stage the 2019 Workshop there. The original 2018 Workshop could not have been held in Ottawa but for the kind assistance of the Librarian and Archivist of Canada, Guy Berthiaume, and the profound knowledge and networks of Paulette Dozois, senior archivist at the Bibliothèque et Archives du Canada. My research assistant/editor Helena Krobath boldly started this project with me in 2020, and Warren Bowen skilfully completed it as research assistant/editor; cover designer-organizer Stephan Struve at Carleton University was a great help, right down to the final day. They have been wonderful to work with. I am lucky that our editor Kate Shuttleworth, Digital Publishing Librarian, Simon Fraser University Library has been so encouraging throughout this complex project. 